\title{
CURRÍCULO E CULTURAS SUBALTERNIZADAS EM ALGUNS PAÍSES DA AMÉRICA LATINA
}

\author{
Emilly Ganum Areal ${ }^{1}$ \\ Valda Inês Fontenele Pessoa ${ }^{2}$ \\ Maria de Jesus Morais ${ }^{3}$
}

RESUMO: Esse artigo tem por objetivo refletir sobre as relações entre currículo e as culturas subalternizadas, perpassando pelas discussões que contribuem com essa relação, como aquelas relacionadas com o debate em torno dos conceitos de interculturalidade, territorialidade e multiculturalidade a partir de autores que pensam a Bolívia, Chile, Peru, Venezuela, México e Brasil, tendo como base o próprio Sul. Utilizando como metodologia a pesquisa bibliográfica, colocam-se em discussão, os conceitos de periferia e de centro, descontruindo-os por meio da compreensão de margem, tendo em Moita Lopes (2008; 2013), Mignolo (2003), Freire (2015), Walsh (2013), Vich (2005), Molina (2008), Candau (2003; 2010; 2012), González (2007), Silva (2005), Veiga-Neto (2002; 2014), Foucault (1992), Larrosa (2016), Santos (1995; 2014; 2016) e Protzel (2015), as principais bases teóricas. Esse ensaio possibilita compreender que a posição da fronteira é a do trânsito, incluindo o trânsito epistemológico e assim sendo, pretende-se, afrontar o fundamentalismo e o essencialismo presentes na modernidade tardia e dessa forma, observar/indicar esses aspectos no campo das práticas curriculares.

PALAVRAS-CHAVE: Currículo. Interculturalidade. Territorialidade. Multiculturalidade.

\section{INTRODUÇÃO}

As reflexões trazidas neste estudo são oriundas das discussões realizadas a partir da disciplina Linguagem, Fronteira e Interculturalidade, oferecida no curso de Doutorado em Letras: Linguagem e Identidade da Universidade Federal do Acre - UFAC. Pretendemos abordar, mesmo que de modo inicial, as relações entre currículo e as culturas subalternizadas, perpassando pelas discussões que contribuem com essa relação, como aquelas relacionadas com o debate em torno dos conceitos de interculturalidade, territorialidade e multiculturalidade a partir de autores que pensam a América do Sul, tendo como base o próprio Sul. Com essa intencionalidade e envolvendo autores que pensam esses aspectos nos países como Bolívia, Chile, Peru, Guatemala, Venezuela, México e Brasil colocamos em discussão, os conceitos de periferia e de centro, descontruindo-os por meio da compreensão de margem, uma forma também de se construir conhecimento, o que se constitui em episteme das margens.

Pensamos esses dois conceitos não em oposição um ao outro, mas em relação um com o outro, pelo híbrido que se transformam. Assim, subsidiando-se em Moita Lopes (2008 e 2013) e em Mignolo (2003) afirma-se que as margens podem ser percebidas como esses entre-luga-

1 Instituição: Universidade Federal do Acre, Orcid: https://orcid.org/0000-0002-3308-9748, E-mail: emilly.areal@hotmail.com 2 Instituição: Universidade Federal do Acre, Orcid: https://orcid.org/0000-0002-0276-0949, E-mail: valdapessoa@yahoo.com.br 3 Instituição: Universidade Federal do Acre, Orcid: https://orcid.org/0000-0002-8053-3549, E-mail: mjmorais@hotmail.com 
res das fronteiras, entendendo que a partir da posição relacionada nesse entre-lugares, outra epistemologia desterritorializada emerge, entendendo o termo desterritorialização relacionado aos que se movem em função de migrações por questões culturais ou sociais, econômicas.

A posição da fronteira é a do trânsito, incluindo o trânsito epistemológico, conforme Moita Lopes (2008), com base no que Mignolo chama de "pensamento das margens", o que exige pensar diferente, tematizar o que não se tematiza, provocar mal estar por conta dessa hibridez que ameaça e contamina. Nessa tentativa de incursão, pretende-se, no limite, afrontar o fundamentalismo e o essencialismo presentes na modernidade, principalmente em tempos de modernidade tardia (Hall, 2002), em que as identidades culturais não são únicas ou centradas e próprias dos indíviduos, posto que esses sujeitos são fragmentados e múltiplos, possuídores de muitas identidades, "algumas vezes contraditórias e não resolvidas" (Hall, 2002, p. 12) e dessa forma, observar/indicar esses aspectos no campo das práticas curriculares. De acordo com Moita Lopes (2008, p. 323), "margens são entre-lugares onde o que é crucial são as incertezas da fronteira e o que aí é vivido". Mignolo e Moita Lopes defendem a ideia de fronteiras fluidas, acreditam numa episteme das margens, pensando "desessencializações sociais de várias naturezas", inclusive as linguísticas e identitárias (Moita Lopes, 2013, p. 9).

Na perspectiva de desenvolver uma educação intercultural crítica, Candau (2012) com base em Catherine Walsh (2009), propõe que se coloque em questão as relações de poder que são construídas, que privilegiam determinados sujeitos e práticas em detrimento de outros. Afirma ainda que é preciso questionar as diferenças e desigualdades entre os diversos grupos socioculturais, enxergando no horizonte a construção de uma sociedade democrática, em que as relações sejam igualitárias e de fato se valorizem aqueles que historicamente foram inferiorizados. Para as autoras, a interculturalidade crítica gera conflito e precisa causar desconforto para diminuir a coesão social. Enfatizam que é necessário colocar em xeque a mera aceitação do outro. Para além desse aspecto, indicam que em uma perspectiva crítica é imprescindível o questionamento da estrutura na qual as relações se dão, uma vez que essa é a condição para penetrar no universo das discriminações, dos preconceitos e dos jogos de poder, presentes na sociedade brasileira. Reconhecer o caráter desigual, discriminador, racista da sociedade contemporânea e que habita dentro de cada um dos sujeitos, permite entendermos esse espaço subalternizado que é o lugar do Outro, compreendendo que tanto o espaço quanto os sujeitos/ alunos, pertencentes aos grupos invisibilizados, aparecem subalternizados.

Nesse sentido, situar a produção dos discursos das políticas curriculares homogeneizadoras dentro desse contexto de compreensão, é o centro do que se tenta fazer ao longo desta discussão, ampliando o debate sobre educação, interculturalismo e culturas subalternizadas em alguns países da America Latina. Candau (2010) com base em Mignolo (2003, 2005) afirma que é necessário visibilizar as culturas subalternizadas pela hegemonia europeia, como por exemplo, os indígenas, quilombolas e negros, sujeitos subalternizados pelo modelo monocultural europeu.

No Brasil, no final da década de setenta, com as "lutas pela democratização", o pensamento de Paulo Freire passa a ser estudado nas universidades brasileiras. Com a abertura política e com as discussões estabelecidas em diversos âmbitos, de certa forma influenciadas pelo repertório teórico desse grande pensador pernambucano, os variados grupos minoritários foram mais visibilizados, mas em uma perspectiva a qual Catherine Walsh denomina de 
interculturalidade funcional. Nessa perspectiva, Pessoa e Melo (2020) embasadas em Walsh (2005), explicitam a conformação desse conceito em um artigo intitulado Currículo intercultural: experiência de construção com o povo Huni Kuin. Para essas autoras, a interculturalidade funcional "atua para conservar o status quo, funcionando especialmente com os grupos hegemônicos, estabelecendo um falso sentimento de mudança nas relações sociais" (PESSOA; MELO, 2020) entre os diferentes grupos.

Para elas, esse processo é constatado a partir da inserção do vocábulo interculturalidade em variados documentos oficiais de países, estados e municípios, como também em diretrizes de organismos internacionais, por decorrência dos recorrentes embates que têm origem nos movimentos dos grupos subalternizados. Cedendo em parte às pressões dos movimentos de reinvindicação desses segmentos sociais, atendem em benefício da coesão social. Por outro lado, essa cessão não tem significado alteração das estruturas de relações que vigoram e têm atuado historicamente. Se faz vista grossa para as diferenças e assimetrias que constituem os grupos, demonstrando uma igualdade que não existe, sem qualquer comprometimento com as questões que tornaram esses segmentos invisibilizados. Os grupos diferentes são tratados de forma igual, conservando as relações de injustiça, restando a manutenção do panorama das relações que historicamente foram construídas.

As lutas indígenas, anteriormente, aconteciam de modo isolado, após os grupos passarem a reunir-se sob uma identidade comum "indígena" ocuparam um certo espaço em âmbito internacional. A partir daí, considerando uma forte exigência por parte dessas populações, como é o caso da Bolívia, cuja população indígena é de cerca de $65 \%$ ou como no Brasil, cuja população é de 0,3\%, conforme López y Sichra (2004), as lutas empreendidas pelos movimentos representativos em defesa desses grupos têm algum grau de reconhecimento, ou me1hor, um reconhecimento a partir da compreensão que norteia a interculturalidade funcional.

Em grande medida, no Brasil, essa difusão se deu a partir da educação popular de Paulo Freire que imbuído do seu compromisso pela luta descolonizadora, teve o papel de apresentar propostas de práticas curriculares comprometidas com a educação dos grupos minoritários, como forma de construir a autonomia dos educandos. Para ele, as ações de definição e implementação curricular implicam na valorização da pluralidade da cultura, dos conhecimentos empíricos de cada grupo e do respeito às individualidades dos sujeitos que vivenciam o processo educativo, que necessariamente envolve diálogo. Por outro lado, essa visão iniciada com a educação popular foi retrocedida pelas políticas de homogeneização curricular, iniciadas no final da década de noventa, embora os documentos oficiais sejam pincelados por termos, como pluralidade, diversidade e outros que caem por terra, com as políticas de avaliação em larga escala que utilizam os mesmos critérios para todos, indistintamente.

Freire (2015) afirma que só é possível ensinar em processo e respaldado socioculturalmente. Nessa conformação, não se trata de um ato de transmissão de conhecimentos unicamente, mas sim e, principalmente, trata-se de criação de oportunidades para a construção de compreensões de saberes já constituídos e de desenvolvimento de outras possibilidades, estabelecendo, dessa forma, caminhos e efetivação de novos saberes, a partir das realidades pensadas. 


\section{PEDAGOGIAS INSURGENTES: INTERCULTURALIDADE}

A ideia de Estado considerado nacional e moderno interessa à concepção de interculturalidade funcional, pois é a partir dessa visão que os sujeitos são conformados, condicionados e facilmente adaptáveis nessa forma de organização. No entender de Walsh (2013), é necessário perguntar de onde falamos e o que estamos pensando. Ela afirma que o Estado segue promovendo o pensamento colonial pela naturalização do imaginário dos grupos hegemônicos. O Estado defende esse pensamento construído exclusivamente dentro das Universidades, criando um imaginário sobre a realidade social dos povos, sobretudo, os do Sul, em especial, o que diz respeito às produções estadunidenses acerca do Caribe e da América Latina. Em contraposição a essa construção de pensamento, Boaventura de Souza Santos cria a expressão "Epistemologias do Sul". Santos $(1995,2014)$ propõe a construção de investigações a partir de epistemologias que desafiem e suplantem as epistemologias produzidas no Hemisfério Norte, que não são capazes de compreender os desafios deste século. Nesse sentido, o termo Sul não se restringe exclusivamente a uma geografia, mas representa metaforicamente as consequências das agruras causadas pelo colonialismo, pelo capitalismo e pelo patriarcado e representa a oposição a essas formas de exploração e tirania, que clama por um conhecimento que não seja colonizador, mas capaz de refletir o mundo a partir de saberes e práticas do Hemisfério Sul.

No entender de Walsh (2013), a produção intelectual é feita, na verdade, pelos povos e movimentos sociais, e não apenas dentro da Universidade. É o que Boaventura de Sousa Santos (2016) diz sobre o conhecimento do sujeito fora da Universidade, fora de uma perspectiva elitista ou apenas científica, mas um conhecimento aberto às classes populares, a negros, indígenas e não restrito a homens e mulheres brancos, provenientes de grupos e países dominantes.

Infelizmente, o "conhecimento" se encontra atualmente pautado pela matriz colonial. É importante, para essa pensadora dos Estudos Culturais da/na América Latina, se colocar o seguinte questionamento sobre o conhecimento: Trata-se de um produto social ou acadêmico? Não é segredo que a maior parte das universidades da América Latina reproduzem a geopolítica do conhecimento do Norte. No dizer de Walsh (2013), os andinos não sabem o que produzem os acadêmicos brasileiros, por exemplo, e vice-versa. Afinal, é preciso problematizar o que entendemos por conhecimento, é algo produzido no Norte, traduzido e aplicado no Sul?

Um exemplo importante diz respeito à Constituição da República Bolivariana da Venezuela que apesar de já ter caminhado em passos largos tematizando a questão indígena, a referida Constituição deixou de abordar questões relativas à população afrodescendente, que soma milhões de pessoas naquele país. Assim, pensar a educação não-formal embasada na decolonialidade proposta por Walsh, aproxima-se do pensamento freireano que foca a discussão nos temas, saberes e práticas locais, tendo como principal vetor do processo o diálogo entre os saberes dos sujeitos participantes, sem a predominante hierarquia que comanda o processo pedagógico atual. A troca dialógica de saberes simétricos entre os participantes é o que Walsh (2013) propõe para promover a necessária decolonialidade. Assim, o pedagógico constitui-se para além do espaço educacional ou escolarizado, quando diz que a pedagogia é 
para ser entendida como metodologia central dentro e por lutas sociais, políticas, ontológicas e epistêmica de libertação.

Nesse diálogo entre Walsh (2013) e Freire (2015), é oportuno mencionar Fanon ${ }^{4}$ (2008), em seu texto Pele negra, máscaras brancas, que nos faz recordar que o importante não é educar negros, mas ensiná-los a não ser escravos dos arquétipos estrangeiros. Ele coloca que o ensino consiste então em capacitar o "suboutro" a tomar uma posição na qual ele ou ela pode se reconhecer e fazer as coisas por si mesmos, agir.

No fim das contas, o tema pedagogia implica nos assuntos no ser e fazer-se humano, por isso, de acordo com Walsh (2013), ela defende pedagogias que apontem e cruzem vertentes contextuais. Primeiro, seguindo Fanon (2008), precisamos pensar pedagogias que permitem repensar a partir da condição ontológico-existencial-racializada dos colonizados, isto é, pensando em desaprender o que é imposto e reconhecido e voltar a refazer o ser. E a segunda compreensão é a de que as noções de pedagogias do "pensar com", implica pensar com os movimentos dos povos indígenas, com organizações afrodescendentes, com grupos economicamente desfavorecidos com e através de lutas sociais, criando condições de transgressão às imposições coloniais, seja dentro ou fora de seus contextos de influência. É necessário esse pensar e agir pedagógicos fundamentados na humanização, seja na educação formal ou informal. Pensar num estado Plurinacional, que reconhece as diferentes culturas dos diferentes povos, faz-se necessário então, questionar o caráter monocultural e etnocêntrico, que estão explícitos ou implícitos na escola e nas políticas educativas e que impregnam os currículos e práticas escolares.

Quanto à tensão entre universalismo e relativismo cultural, de grande relevância para a ação educativa, em especial para as questões curriculares, é preciso que nos situemos de maneira crítica, seja no que se refere aos chamados conhecimentos e valores considerados "universais", quase sempre centrados na cultura ocidental europeia e cuidar para não cairmos num relativismo absoluto, reduzindo os conhecimentos e valores veiculados pela educação formal a um determinado universo cultural, o que levaria à guetificação (CANDAU, 2003).

Por outro lado, para Vich (2005), a interculturalidade não pode se limitar à educação, nem ao mundo indígena, como esse autor afirma ser a situação dos programas específicos bilíngues do sistema educacional peruano. Para ele, o que acontece nessas experiências é uma visão alijeirada que compromete a perspectiva intercultural, reduzida a a festas, danças, comidas, dando-lhe um enfoque folclórico e nostálgico que não contribui para alterar o status quo das relações. O interculturalismo pressupõe condições de diálogo, o que requer uma agenda política de transformação, que recusa-se a ver a cultura como não conflitiva, a diversidade precisa ser afirmada dentro de uma política crítica e de compromisso com a justiça social. Na continuidade, passaremos a outras discussões que contribuem com a relação entre currículo e as culturas sulbalternizadas.

4 É oportuno enfatizar que ao aproximarmos Walsh, Freire e Fanon não nos interessa fazer uma exegese da obra desses três pensadores. Neste texto, o que nos move nessa aproximação é acentuar o caráter libertador que eles abordam ao tratar da educação indígena, do proletário/grupos economicamente desfavorecidos e do negro. Liberdade em relação aos determinismos culturais e econômicos de alguns grupos sobre outros. 


\section{TERRITORIALIDADE E MULTICULTURALIDADE}

Em Molina (2008), a partir da discussão empreendida sobre territorialidade e multiculturalidade, é possível observar o caso da Bolívia e dos Chiapas no México, os casos mais ricos na América Latina para se refletir essa discussão. Essa experiência da autonomeação política dos povos zapatistas do Sul do México é uma referência onde os processos educacionais acontecem conforme os contextos onde estão localizadas as escolas de resistência, onde a necessidade da comunidade visando seu autodesenvolvimento é levada em consideração. Nos termos de Walsh (2013), é legítimo afirmar que a interculturalidade crítica é exercitada na prática, num espaço onde as demandas dos camponeses indígenas é valorizada e levada em conta.

Nessa experiência do México paira o compromisso com a descolonização da sociedade. Nela é dada a devida importância à cultura e às necessidades locais, orientando e situando o debate, ou seja, as discussões emergem da periferia. Os zapatistas construíram dinâmicas internas próprias, voltadas para a manutenção de formas de vida a partir de perspectivas anti-imperalista e contra-hegemônica, resistindo ao capital e ao poderio neoliberal, além das forças do Estado mexicano. O movimento zapatista encontrou caminhos para defender e preservar suas culturas, os direitos fundamentais dos seus povos e seus territórios. Para Zibechi (2006), o movimento zapatista suscitou diversas discussões sobre o papel que desempenha o Estado e suas instituições, as práticas do movimento foram capazes de responder às demandas sociais, indo além das perspectivas políticas ou acadêmicas.

Cerca de cento e setenta e nove organizações sociais participaram da Campaña Nacional en Defensa de La Madre Tierra y el Territorio ${ }^{5}$, realizada entre 10 de abril e 20 de novembro de 2016, implica dizer que houve uma significativa participação social daqueles povos, realizaram assembleias, congressos e debates em âmbito local e internacional, as diversas vozes ecoaram num movimento claro contra os desmandos do governo mexicano. Os falares e fazeres zapatistas tiveram ressonância, ecoaram de diversos modos e formas. A capacidade de sentir dos povos indígenas foi responsável por promover uma reviravolta social, essa experiência aponta para caminhos outros e sinaliza para mundos com menos injustiça social.

No caso da Bolívia, num primeiro momento, é possível entender esse trânsito de reconfiguração nos Altiplanos a partir da década de 1970. Num segundo momento, pode-se enxergar o que antecede o socialismo na Bolívia, com a ascensão de um governo de lutas emancipatórias de combate à colonialidade, é inegável que a conquista do território é um passo importante, uma Bolívia complexa e multifacetada exige além da conquista do território, o estabelecimento e articulação com outras questões, como por exemplo: revitalização da língua, reafirmação da cultura. A marcha do território até La Paz antes de Evo Morales assumir o governo, foi uma espécie de tentativa de construir uma identidade amazônica a partir da Bolívia, é o que González (2007) chama de Colonialismo interno, esse movimento que não é exclusivo do centro/periferia, mas também dentro e na periferia.

Pensando na discussão acerca da autonomia, uma vez que, falamos de território, podemos citar o caso do México, como um caso muito importante dentro da América Latina, em função de três circunstâncias. A primeira, porque parte sempre da perspectiva da recomposição, depois, porque entende que as autonomias departamentais possibilitariam o pluralismo.

5 Página oficial da campanha disponível em <http://www.defensamadretierra.mx $>$. 
Por fim, por tratar-se de uma dimensão emancipatória, em função de que parte de lutas anticapitalistas que de algum modo forja alianças mais socialistas. Isto porque autonomias é uma demanda de todos e cara a todos, que impõe uma pluralidade de desdobramentos que nega "o caminho" diante da diversidade dos mundos. É o caso da negação da negação, que pensa esse mundo, cabendo muitos mundos, que pressupõe pensá-los fora das margens.

A partir dessa compreensão e apoiadas na discussão que Silvia Rivera (2015) faz, coloca-se em questão o multiculturalismo, entendido como um empreendimento dos governos neoliberais de congregar os interesses dos movimentos indígenas e as políticas econômicas, que mutila os vários mundos culturais. Esse discurso do multiculturalismo é o resultado da hibridização de visões essencialistas e historicistas das questões indígenas, que não têm nenhum interesse de tratar as questões de descolonização, mas camuflam e renovam práticas de subalternização e colonização.

Essa pensadora menciona que as oligarquias tentaram uma espécie de gatopardismo, na perspectiva de que é preciso modificar as coisas para que elas continuem como estão. É necessário criar essa "cortina de fumaça", usando o etnoturismo, por exemplo, para inebriar o cenário, criando uma agenda culturalista. O gatopardismo das elites políticas e econômicas da América Latina que se reproduz na região andina é uma espécie de "colonialismo interno", conforme definiu Pablo González Casanovas (2007), essas estruturas se articulam com os centros do poder do Norte, através das Universidades, Fundações e Organismos Internacionais.

O adorno cultural do multiculturalismo na Bolívia é muito marcado por essa forma de compreensão e orienta a inclusão condicionada, essa cidadania sujeita e de massas que subalternizam as identidades tanto em Gonzalo Sánchez de Lozada ${ }^{6}$, ex-presidente boliviano, cujo legado dá conta de uma enorme instabilidade social proveniente de manifestação populares contra a sua política referente aos recursos energéticos do país, resultando na sua renúncia após vários protestos violentos em 2003, quanto nas ONGs balizadas por ideias neoliberais. É cada vez mais visível o alinhamento político, econômico e ideológico que assegura às ONGs e o Terceiro Setor serem os principais articuladores na implementação das políticas neoliberais na década de 1990, exercendo praticamente o papel de "assessorias" e os "grandes" parceiros dos governos.

Mesmo com a promulgação da Constituição Federal de 2008, na Bolívia, que assegura autonomia no território conforme tradições e costumes, a autonomia municipal, departamental e regional, com mais cadeiras no parlamento para os indígenas, com o rechaço à exploração do petróleo, com a resistência a abertura de territórios indígenas, essa lógica rompe com a reprodução colonial e se coloca/apresenta como um conjunto de políticas para essa população.

É óbvio que houve uma repercussão de caráter mais geral, na perspectiva das línguas, por exemplo. No período de gestão, compreendido entre 2006 a 2009, quando Lozada renunciou ao cargo, os currículos no ensino tiveram e têm desdobramentos que colocam em curso esse enfrentamento na prática, gerando várias indagações: As identidades na Amazônia Boliviana antes de 2006 e agora em 2019 se diferenciam? Os dilemas de domínio do território e

6 Gonzalo Sánchez de Lozada foi presidente da Bolívia em dois períodos, compreendidos de seis de agosto de 1993 a seis de agosto de 1997 e de seis de agosto de 2002 a dezessete de outubro de 2003. 
suas relações com as identidades se repetem? De que maneira essas mudanças vão repercutir no processo educacional, no currículo com tantas línguas oficiais? É possível pensar o território a partir de sua materialidade, nessa luta contra a colonialidade, na descolonização pela negação da negação, numa perspectiva da filosofia do bem viver, rompendo com essa lógica do desenvolvimento sustentável das ONGs e da economia verde, do capitalismo verde?

Esse debate, infelizmente, não acontece na academia, é um debate enclausurado, na Bolívia essa discussão acontece, o boliviano não se considera etnia, mas sim, povo. Essa construção de ser amazônico, com seus 34 (trinta e quatro) povos e mais os mestiços (caraianas), são inegáveis os conflitos com os mestiços e indígenas, nessa disputa de quem são os povos originários.

Esse espaço de disputa entre Pando e Beni, a parte "de baixo" tem conflito com os povos ao Norte, os tidos como "originários". Beni tem sua forte ligação com a pecuária, são considerados os guardiões das fronteiras, os esquecidos da nação, já Pando tem a posição estratégica na economia, goza de prestígio comercial. É inegável que a diminuição dessas assimetrias sociais possibilita uma maior integração e fortalece a democracia, nesse diapasão, o multiculturalismo até reconhece a existência da diferença, entendendo que o outro existe, mas ele sempre será o outro, desse modo, corrobora para essa cidadania mutilada.

Nesse sentido, o estado brasileiro teve mais eficácia do que nas Américas Hispânicas, a lógica da colonização portuguesa foi introjetada "a ferro e fogo" e regula, estabelecendo essa unidade, repercutindo fortemente no seu interior. É o caso, por exemplo, das feiras culturais, em Guajará-Mirim, no vizinho estado de Rondônia, festas interculturais, Brasil a fora. Esse debate rico que acontece na Bolívia, não acontece nas bandas de cá. Nosso governo federal, por exemplo, enxerga essa imagem do outro como expressão do atraso, a ideia é manter-se como está, o discurso hegemônico da identidade única se reflete como mera atualização do domínio colonial, conforme Molina, Vargas e Soruco (2008).

\section{AS PRÁTICAS CURRICULARES E SUA INTERFACE COM A INTERCULTURALIDADE, TERRITORIALIDADE E MULTICULTURALIDADE}

Na perspectiva educacional, se pensarmos o currículo de uma forma geral e de acordo com Silva (2005), observaremos que é indissociado, enredado naquilo que somos, naquilo que nos tornamos, nos nossos processos identitários, na nossa subjetividade, ou seja, o currículo é também uma questão de identidade.

A noção de currículo que defendemos, guarda relação direta e inseparável com a cultura, está intimamente ligado com a compreensão acerca das relações que reproduzem as desigualdades, entendendo que ele não pode ser compreendido sem a devida análise das relações de poder que o envolve e desprendido das questões ligadas ao local, ao gênero, à religiosidade e aos diferentes grupos sociais. Conforme corrobora Veiga-Neto (2002), currículo é uma porção da cultura, guarda estreita correspondência com a cultura na qual ele se organizou, de modo que ao analisarmos um determinado currículo, podemos inferir não só os conteúdos tidos como importantes naquela determinada cultura, como também porque aquela cultura prioriza alguns conteúdos em detrimento de outros. O currículo se situa no cruzamento entre a escola, a cultura e o poder. 
Nessa direção, Veiga-Neto (2014) com base em Foulcault (1992), aborda as críticas aos processos de disciplinarização e normalização que acontecem em instituições modernas como a escola, a prisão, os hospitais e as fábricas. Foulcault, segundo Veiga-Neto nos mostra que práticas e políticas educacionais podem ser compreendidas de maneiras muito ricas e diferentes das tradicionais, talvez seja o que nossos países vizinhos e menores do ponto de vista econômico estejam nos ensinando, como é o caso da Bolívia, por exemplo.

Nessa mesma condição de incerteza do processo de significação cultural dos sujeitos, conforme afirma Brait (2013), Bakhtin e o Círculo de Viena viam a língua sofrer influências do contexto social, da ideologia dominante e da luta de classes. Por isso, era ao mesmo tempo produto e produtora de ideologias. A língua só existe em função do uso que locutores e interlocutores fazem dela em situações de uso. Além disso, um enunciado sempre é modulado pelo falante para o contexto social, histórico, cultural e ideológico, caso contrário não será compreendido.

Nessa perspectiva, Larrosa (2016), diz que o ser humano é um vivente dotado de palavras. Para ele, o ser humano não pensa por ideias, pensa por palavras na medida em que elas dão sentido ao que somos e ao que nos acontece. Recorre a Walter Benjamin (1994) quando diz que o nosso mundo vive uma pobreza de experiência e afirma que se a experiência é o que dá sentido à escrita, a falta de tempo, o excesso de opinião, o excesso de trabalho nos tira a possibilidade de que algo nos aconteça. Nessa condição, chegamos ao fim do dia e nada temos a contar, o relato parece desaparecer. A linguagem diz quase tudo o que somos e, "[...] determina a forma e a substância não só do mundo, mas também de nós mesmos, de nosso pensamento e de nossa experiência" (LARROSA, 2016). Línguas e linguagens que parecem neutras, despovoadas, "grandes", que buscam produzir, legitimar e controlar certas linguagens, certas línguas, certas verdades, essa tensão entre o modelo dominante de linguagem que regulamenta o "como" escrever no campo educacional, acaba invisibilizando quem escreve, o sujeito, legitimando o universal, gélido e conformador.

Nessa tensão de ser expropriado de sua experiência, desse espaço subalternizado, que é o lugar desse "outro", nessa relação de subjetividade de como isso é pensado, tentar situar um pouco de como isso é refletido na produção do discurso é um desafio que nos parece eminente a ser transposto. Como também é importante aproximar o território, fazendo um exercício de pensar a interculturalidade em uma outra dimensão, mostrando em alguma medida as dificuldades para aceitação interna dos diálogos, trânsitos, discutindo essas relações de poder mediadas pelo espaço, mas com a dimensão mais ampla do poder simbólico e no modo como se racionaliza essa relação. Tratar o território como estratégias de poder e formas de sobrevivência, discutindo o currículo como encarnado e reflexo da cultura desse sujeito social.

Tentou-se trazer à baila algumas discussões que pretendem acomodar através do multiculturalismo, o apagamento desse sujeito social, que ganha mais atenção após as chamadas viradas pós-estruturalista, discursiva, pós-colonial, trazendo reflexões sobre o diálogo Sul-Sul, propondo uma agenda que pense o Sul a partir do Sul e não a partir do hemisfério Norte, conforme sugere Ângela Kleiman, a partir do que Moita Lopes (2013) chama "as vozes do Sul".

Candau (2010) sugere uma discussão menos geral, conforme propôs Protzel (2015), parte de uma perspectiva mais específica, analisa de forma mais detalhada o caminho. Assim, no panorama que se mostra, resgata-se inicialmente o pensamento de Protzel (2015). Con- 
siderando a situação geopolítica do seu país, esse autor sugere deslocamentos para refletir a interculturalidade em uma outra dimensão.

Nessa perspectiva, fomenta a saída do centro para a periferia, na tentativa de perceber a produção desse Outro. Protzel, na mesma obra, parte da realidade peruana, para afirmá-la múltipla, diversa, que tem marcadamente suas expressões internas divididas entre o litoral, a serra e a selva e, seus sujeitos que integram esses territórios. O autor reitera as formas de dominação, mas estabelece diferenças entre o colonizador ibérico e anglo- saxônico, apontando como o sistema atua para se manter como está. Protzel (2015), aborda a questão intercultural como uma ideia e um fato, a partir da intensificação das migrações internas e internacionais no mundo, refletindo as implicações e concepções tão diversas quanto as culturas predominantes nas regiões de intercâmbio. Afirma que essas diferenças favorecem certos interesses e abordagens políticas às custas de outras, o que cria dificuldades para a existência de uma corrente comum e nessa perspectiva, a América Latina ocupa um lugar único, o autor parte de uma dimensão mais ampliada para discutir as questões interculturais.

Articulada à perspectiva de Paulo Freire, Candau (2010) delineia a sua compreensão de currículo em uma perspectiva crítica, entendendo-o não como um desenho fixo e planificado, a ser estendido nacionalmente a qualquer grupo, independente do perfil sociocultural. Necessariamente, ele se modifica a partir do grupo ao qual se destina, efetivando propostas interculturais no sentido pleno da palavra. Assim compreendendo, reafirma a possibilidade de arquiteturas pluricurriculares, envolvidas em multilinguísticas, construídas com os sujeitos do processo e não para eles, de forma exteriorizada, tão comum e naturalizadas na contemporaneidade. Será por essa perspectiva que se irá ao encontro da diversidade dos grupos heterogêneos que constituem a sociedade de um país.

Segundo Candau (2010), o arremedo, chamado de "currículo plural", vem sendo institucionalizado em maior ou menor grau em alguns países da América Latina, como é o caso do Chile, Bolívia, Guatemala e do Paraguai, por exemplo. Essa interculturalidade chega a América Latina na perspectiva da Educação, especificamente da educação escolar indígena, na direção de assimilação desse "outro", na perspectiva de introduzir alguns conteúdos relativos a diferentes culturas, sem que esse currículo seja afetado como um todo, mas apenas de modo pontual, onde tenha o predomínio da "cultura comum", dos conhecimentos e valores considerados "universais", na perspectiva da interculturalidade funcional, que é acomodar o "outro", em uma dimensão hegemônica, planificadora. A perspectiva crítica de interculturalidade foi o foco de nosso interesse e que foi defendido neste ensaio.

\section{CONSIDERAÇÕES FINAIS}

Ainda que de modo embrionário, longe de pretender esgotar uma discussão tão cara e ampla, buscou-se nesse ensaio contribuir para as discussões, a partir dos atuais debates no contexto latino-americano, onde reformas educacionais nos diferentes níveis são empreendidas e tentam invisibilizar processos pedagógicos próprios, decoloniais, intenta-se fugir e rexistir àquilo que é imposto pela colonialidade do conhecimento e do poder. Assim, a nossa atenção esteve voltada para as relações estabelecidas entre currículo e as culturas subalternizadas, perpassando pelas discussões que contribuem com essa relação, como aquelas relacionadas com o debate em torno dos conceitos de interculturalidade, territorialidade e multiculturali- 
dade. Entendemos que essas discussões contribuem para alargar as possibilidades de transformações curriculares, ajudando a reconstruir outros imaginários sobre a questão, avançando na problematização dessa "cultura comum", dos conhecimentos e dos valores considerados "universais". Compreendemos que se não forem colocadas em xeque essas questões, em confronto com exemplos extraídos do contexto dos grupos diferentes, situando esse debate no centro das discussões, não se avança na compreensão da injustiça das formulações curriculares tecnocratas vigentes. Sem entender as diferentes cosmovisões, os diversos saberes dos inúmeros grupos socioculturais, não se consegue repensar a epistemologia dominante.

É condição sine qua non essa compreensão, para possibilitar a construção de propostas curriculares interculturais de fato, desenvolvidas com/e a partir de práticas interculturais nos diferentes âmbitos sociais. Essa perspectiva é mais do que pensar os currículos propriamente ditos, pressupõe pensar uma nova concepção de Estado, de democracia, de cidadania, em que a interculturalidade crítica é questão central porque coloca em foco as relações de poder que são construídas, onde se privilegiam determinados sujeitos e práticas em detrimento de outros, a interculturalidade crítica gera conflito, desconcerto na lógica social. Nesse sentido, ela tem um papel central, articula igualdade e diferença, contribuindo para a construção de saberes e práticas comprometidas com o fortalecimento da democracia e emancipação social.

\title{
CURRICULUM AND SUBALTERNIZED CULTURES IN SOME LATIN AMERICAN COUNTRIES
}

\begin{abstract}
This present article goals to reflect about the relations between, curriculum, and subalternized cultures, going through the discussions that contribute to this relationship, such as those related to the debate around the concepts of the Bolívia, Chile, Peru, Venezuela, México e Brasil itself as their basis. Using the bibliographical research as methodology, we discuss the concept of periphery and downtown, deconstructing them through the comprehension of margin, taking as main theoretical basis authors such as Moita Lopes (2008; 2013), Mignolo (2003), Freire (2015), Walsh (2013), Vich (2005), Molina (2008), Candau (2003; 2010; 2012), González (2007), Silva (2005), Veiga-Neto (2002; 2014), Foucault (1992), Larrosa (2016), Santos (1995; 2014; 2016) e Protzel (2015). This essay enables us to comprehend that the edge position is the transit position, including epistemological transit. We intend to face the fundamentalism and the essentialism present in late modernism and, in this way, observe/indicate these aspects in the curricular practices area.
\end{abstract}

KEYWORDS: Curriculum. Interculturality. Territoriality. Multiculturality.

\section{REFERÊNCIAS}

BENJAMIN, W. Experiência e Pobreza. In: Magia e técnica, arte e política. 7. ed. Tradução: Sérgio Paulo Rouanet; prefácio: Jeanne Marie Gagnebin. São Paulo: Brasiliense, 1994.

BRAIT, B. (org.) Bakhtin, dialogismo e construção do sentido. 2. ed. Campinas, Editora da Unicamp, 2013.

CANDAU, V. M. F. Educação intercultural no contexto brasileiro: questões e desafios. In: SEMINÁRIO INTERNACIONAL DE EDUCAÇÃO INTERCULTURAL, GÊNERO E MOVIMENTOS SOCIAIS, 2., 2003, Florianópolis. Anais. Florianópolis: Universidade Federal de Santa Catarina, 2003.

CANDAU, V. M. F. Educacion Intercultural en America Latina: distintas concepciones y tensiones actuales. Estudos Pedagógicos, Valdivia/Región de los Ríos, Chile, vol. 36, n. 2, 2010.

CANDAU, V. M. F. (Org.) Reinventar a escola. 7. ed. Petrópolis: Vozes, 2010.

CANDAU, V. M. F. (Org.). Didática crítica intercultural: aproximações. Petrópolis (RJ): Vozes, 2012. 
FANON, F. Pele negra, máscaras brancas. Salvador: EDUFBA, 2008.

FREIRE. P. Pedagogia da autonomia: saberes necessários à prática educativa. 51. Ed., Rio de Janeiro: Paz e Terra, 2015.

FOUCAULT, M. Microfísica do Poder. 10ª ed. Rio de Janeiro: Graal, 1992.

GONZÁLEZ C. Colonialismo interno (uma redefinição). CLACSO, Consejo Latinoamericano de Ciencias Sociales, 2007.

HALL, S. A identidade cultural na pós-modernidade. Rio de Janeiro: DP\&A, 2002.

LARROSA, J. Tremores: escritos sobre experiência. Tradução de Cristina Antunes e João Wanderley Geraldi. Belo Horizonte (MG): Autêntica Editora, 2016.

LÓPEZ, L. e SICHRA, I. La educación en áreas índigenas de América Latina: balances y perspectivas. In: HERNAIZ, I. (org.). Educación en la diversidad. Experiencias y desafíos en la educación intercultural. Buenos Aires: IIPE. 2004.

MIGNOLO, W. D. Historias Locales/diseños globales. Colonialidad, conocimientos subalternos y pensamiento fronterizo. Akal Ediciones, Barcelona, 2003.

MIGNOLO, W. D. Colonialidade: O lado mais escuro da modernidade. University, Durham, NC, EUA. Pontifícia Universidade Católica do Rio de Janeiro (PUC-Rio), Rio de Janeiro - RJ, Brasil. DOI 10.17666/329402/2017. 2003. Disponível em <http://www.scielo.br/pdf/rbcsoc/v32n94/01026909-rbcsoc-3294022017.pdf>. Acesso em: 15 jan. 2020.

MIGNOLO, W. D. A colonialidade de cabo a rabo: o hemisfério ocidental no horizonte conceitual da modernidade. In: LANDER, E. (Org). A colonialidade do saber: eurocentrismo e ciências sociais. Perspectivas latino americanas. Buenos Aires: 2005.

MOITA LOPES L. P. Inglês e Globalização em uma epistemologia de fronteira: ideologia linguística para tempos híbridos. D.E.L.T.A., vol. 24, n. 2, 2008.

MOITA LOPES, L.P. (Org.). Linguística aplicada na modernidade recente: Festschrift para Antonieta Celani. São Paulo (SP): Parábola, 2013.

MOLINA W.; VARGAS C. e SORUCO P. Estado, identidades territoriales y Autonomías en la región amazónica de Bolívia. La Paz. PIEB, 2008.

PESSOA, V. I. F.; MELO, L.de F. Currículo intercultural: experiencia de construção com o povo Huni Kuin. Revista Espaço do Currículo, v. 13, n. 1, jan./abr. 2020, p. 47-57.

POSTERO, Nancy Grey. Movimientos indígenas bolivianos: articulaciones y fragmentaciones en busqueda de multiculturalismo. In: ENRIQUE, Lopez; REGALSKY, Pablo (Org.). Movimientos indígenas y Estado en Bolivia. La Paz: Editora Proeib Andes, 2005.

PROTZEL, J. Comunicación intercultural: confrontando concepciones y problemas. Venezuela, Correspondencias \& Análisis, No 5, año 2015.

RIVERA CUSICANQUI, S. Sociología de la imagen. Miradas ch'ixi desde la historia andina. Buenos Aires, Tinta Limón, 2015.

SANTOS, B. de S. Towards a New Common Sense. Law, science and politics in the paradigmatic transition. New York, London: Routledge, 1995.

SANTOS, B. de S. Epistemologies of the South: Justice Against Epistemicide. Boulder: Paradigm Publishers, 2014.

SANTOS, B. de S. Para uma nova visão da Europa: aprender com o Sul. Sociologias, Porto Alegre, ano 18, n. 43, p. 24-56, set./dez. 2016. Disponível em: http://dx.doi.org/10.1590/15174522-018004302. Acesso em: 1 out. 2019.

SILVA, T. T. da. Documentos de identidade: uma introdução às teorias do currículo. Belo Horizonte: Autêntica, 2005.

VEIGA-NETO, A. Cultura e currículo. Contrapontos, 2(4):43-51, 2002.

VEIGA-NETO, Alfredo and RECH, T. L. Esquecer Foucault? Pro-Posições [online]. 2014, vol.25, n.2, pp.67-82. ISSN 1980-6248. http://dx.doi.org/10.1590/S0103-73072014000200004.

VICH, V. Las políticas culturales en debate: lo intercultural, lo subalterno y la dimensión universalista. 
El Estado está de vuelta: desigualdad, diversidad y democracia. Lima: Instituto de Estudios Peruanos (IEP), 2005, pp. 265-278.

WALSH, C. (Ed.). Pedagogías decoloniales: prácticas insurgentes de resistir, (re)existir y (re)vivir Tomo I. Quito (Ecuador): Ediciones Abya-Yala, 2013.

ZIBECHI, R. E1 Zapatismo y América Latina. In. Revista Contrahistorias: La outra Mirada del Clio. Dossier: La otra Campaña. Morelia: México, Jitanjáfora Morelia Editorial, n. 6, mar-ago 2006.

Data submissão: 05/06/2020

Data aprovação:23/06/2020 